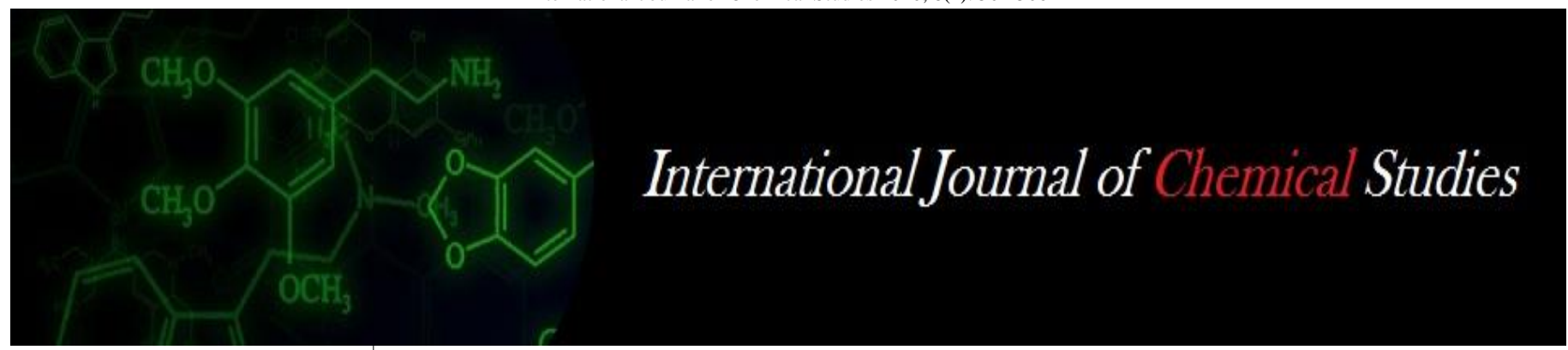

P-ISSN: 2349-8528

E-ISSN: 2321-4902

www.chemijournal.com

IJCS 2020; 8(2): 502-506

(C) 2020 IJCS

Received: 16-01-2020

Accepted: 21-02-2020

Ajay Lavishkar

Department of Forestry

Jawaharlal Nehru Krishi Vishwa

Vidhyalaya, Jabalpur, Madhya

Pradesh, India

Vijay Bagare

Department of Forestry

Jawaharlal Nehru Krishi Vishwa

Vidhyalaya, Jabalpur, Madhya

Pradesh, India

Sandeep Kumar

Research Scholar Forest

Research Institute, Dehradun

Uttarakhand, India
Corresponding Author Ajay Lavishkar

Department of Forestry Jawaharlal Nehru Krishi Vishwa

Vidhyalaya, Jabalpur, Madhya

Pradesh, India

\section{Growth performance of wheat varieties under different pruning intensities of Dalbargia sissoo based Agri-silviculture system}

\author{
Ajay Lavishkar, Vijay Bagare and Sandeep Kumar
}

DOI: https://doi.org/10.22271/chemi.2020.v8.i2h.8815

\begin{abstract}
A field experiment was carried out at Dusty Acre Research Farm, Department of Forestry, JNKVV, Jabalpur to assess the growth performance of wheat varieties in 13 year old Dalbergia sissoo plantation. Maximum grain yield of wheat was recorded when grown under open condition $\left(27.20 \mathrm{q} \mathrm{ha}^{-1}\right)$. Among different pruning intensities, significantly maximum grain yield was recorded under $75 \%$ pruning $(24.4 \mathrm{q}$ $\left.\mathrm{ha}^{-1}\right)$ which inturn was significantly superior to $50 \%$ pruning $\left(21.27 \mathrm{q} \mathrm{ha}^{-1}\right)$ and $25 \%$ pruning $\left(19.47 \mathrm{q} \mathrm{ha}^{-}\right.$ $\left.{ }^{1}\right)$. No pruning recorded significantly lowest grain yield $\left(17.74 \mathrm{q} \mathrm{ha}^{-1}\right)$. The percent reduction in grain yield under no pruning $25 \%, 50 \%$ and $75 \%$. Pruning as compared to open condition was $34.75 \%$, $28.41 \%, 21.80 \%$ and $10.29 \%$ respectively. Wheat varieties showed no significant effect on straw yield, however variety Sujata recorded higher straw yield as compared to variety MP 3173 and MP 3288 . Different wheat varieties showed significant effect on harvest index. Variety MP 3288 recorded significantly higher harvest index (34.96) followed by MP 3288 (33.90). Variety Sujata recorded lowest harvest index (32.51).
\end{abstract}

Keywords: Agri-silviculture, Pruning, Pruning intensities, Agroforestry.

\section{Introduction}

Majority of Agricultural crops grown with Agroforestry trees and relatively poor yielder due to shade of trees. Shade intensity has strong negative effects on the performance of under storey crops (Singh, 1993) ${ }^{[5]}$. Light is a critical factor affecting the performance of field crops under Agroforestry intervention. It is the general apprehension of the farmers that trees in association with crops in Agroforestry was compete strongly with crops for nutrients and moisture (Dhyani et al., 1990) ${ }^{[2]}$.This competition between trees and crops increased with increasing age of tree due to increase in canopy (due to shade). Reduction in yield due to tree shade may be reduced by manipulation in tree canopy which can help to associated crop. There are number of silvicultural operations which can reduce tree canopy, facilitated entry of sunlight, pruning is one of them. Pruning increases the flexibility of agroforestry system, and enables farmers to balances their individuals needs for tree crop products. Pruning provides woody biomass for fire wood, leaf biomass and fodder. In pruning the removal of some part of the tree or crown was obviously reduce the competition ability of tree because crown management was facilitate more light to underneath crops and reduce demand of moisture and nutrients.

So, management practices are very necessary to get optimum production from an Agrisilviculture system. Pruning reduced the competitive ability of the trees which allow the crop to take advantage of the higher nutrient availability under the alley cropping system (Hagger $e t$ al., 1993) [3]. The research work carried out in past is very scanty and gives very little information on compatibility of crop species varieties and trees, spatial effect of trees on crops.

\section{Material and Method}

The Present investigation or Experiment was conducted at Dusty Acre Research Farm, Department of Forestry, Jawaharlal Nehru Krishi Vishwa Vidhyalaya, Jabalpur during Rabi season of 2012 in 13 year old Dalbergia sissoo based Agri-silviculture. Jabalpur is situated at $23^{\circ}$ 9' North Latitude and 79.58' East longitude at an altitude of 411.78 meters above the mean sea level. It comes under the agroclimatic region classified as Kymore plateau and 
Satpura hills and is broadly known as rice-wheat crop zone of Madhya Pradesh. This region has typically arid \& semi-arid zone climate with hot dry summer and cold winters.

The mean annual rainfall of Jabalpur is $1350 \mathrm{~mm}$ mostly received between mid of June to September with occasional rains during winter. The mean monthly temperature goes down to the limit of $4^{\circ} \mathrm{C}$ during winter, while the maximum temperature reaches as high as $45{ }^{\circ} \mathrm{C}$ during summer. Generally relative humidity remains very low during summer (15 to $30 \%$ ), moderate (60 to $75 \%$ ) during winter and it attains high value (80 to $95 \%$ ) during rainy season.

Sujata: The variety "SUJATA" is rainfed wheat evolved from Jawaharlal Nehru Krishi Vishwa Vidyalaya, Jabalpur (M. P.) during the year 1994. The plants is 90 to $100 \mathrm{~cm}$. tall. It is early maturing (120 to 125 days) variety. The earhead are $9 \mathrm{~cm}$. long with long grains having test weight of 30-36 gram. It produces about 20 to 25 quintal grains per hectare. Sujata is rainfed (without providing irrigation but with conservation with moisture) variety. If it is cultivated under better management its yielding ability may be enhanced.

MP 3173: The variety is released by J.N.K.V.V Jabalpur M.P. It's suitable under rainfed as well as irrigated condition and tolerant to drought. It matures in 125 days. Yield potential is 23-25qt/ha-1 in rainfed and 37-40qt/ha-1 in limited irrigation condition. It is non-lodging and non-shattering variety. Grain are lustrous and bold, tolerant to rust. It has ability to sustain irrigation and responsive to fertilizer. Test weight is $40 \mathrm{gm}$.

MP 3288: Wheat variety MP-3288 developed at JNKVV, Jabalpur. It is semi dwarf, sarbati, bold, and has shining grains with resistance to rust and other diseases, tolerant to heat and drought. It is high yielding, matures in 118-122 days and is suitable for chapatti with good quality attributes.

\section{Pre-harvest observations}

To record various observations five places (1 meter row length) in each plot were randomly selected, tagged 15 days after sowing of the crop marked both end by putting wooden sticks.

\section{Plant population}

Plant Population per meter row length was recorded 15 days after sowing at three randomly selected spots in each plot.

Height of the Plant Height of 5 randomly marked plants were measured in centimeter from the ground level up to the auricle of the upper most fully opened leaf at the stage of crown root initiation (CRI), late tillering (LT), late jointing (LJ), flowering (F), milking (M), dough (D) stage. The mean height was calculated by dividing the summation with five.

\section{Numbers of tillers per meter row length}

Total number of tillers per meter row length at all growth stages of the crop (i.e. CRI, LT, LJ, F, M and Dough) and at harvest were recorded by counting from five marked row in each plot and the mean values were calculated.

\section{Grain yield (kg ha-1)}

The producer of the net plot was tied in bundles and their weights were recorded by using spring balance. After threshing the grain from each bundle, the weight of clean grain per plot was recorded accurately. The grain yield per hectare was obtained by multiplying the net plot yield by converting factor $\left(10,000\right.$ divided by net area $\left(\mathrm{m}^{3}\right)$ of plot). The yield was expressed in kilograms per hectare.

\section{Straw yield $\left(\mathrm{kg} \mathrm{ha}^{-1}\right)$}

The straw yield of each plot was obtained by subtracting the grain yield from total weight of the bundles per plot. The straw yield per hectare was obtained by multiplying the net plot yield by the converting factor $(10,000$ dividing by net area $\left(\mathrm{m}^{2}\right)$ of plot). The yield was expressed in kilograms per hectare.

\section{Harvest Index}

Harvest index is expressed as the ratio of economic yield (grain yield) to the total biological yield (grain yield + straw yield) and expressed in percentage. It was calculated as per the formula proposed by Nichiporovich (1967).

$$
\text { Harvest Index }=\frac{\text { Economic Yield }}{\text { Biological Yield }} \times 100
$$

\section{Result and Discussion \\ Germination percentage}

The germination percentage is one of the most important factors which contribute towards crop growth and ultimately crop yield. The number of seeds germinates/MRL were recorded 15 days after sowing. The data were statistically analysed. The mean germination\% per meter row persist under different treatment is given in Table 1.

Table 1: Effect of different pruning intensities of Dalbergia sissoo on germination percentage of different varieties of wheat in Agrisilviculture system.

\begin{tabular}{|c|c|}
\hline Treatment & $\begin{array}{c}\text { Germination percentage (per meter } \\
\text { row length) }\end{array}$ \\
\hline \multicolumn{2}{|c|}{ Pruning Intensities } \\
\hline $\mathrm{P}_{0}$-No pruning & 51.73 \\
\hline $\mathrm{P}_{25}-25 \%$ pruning & 52.40 \\
\hline $\mathrm{P}_{50}-50 \%$ pruning & 50.40 \\
\hline $\mathrm{P}_{75-75 \% \text { pruning }}$ & 49.43 \\
\hline Open-No tree & 52.40 \\
\hline \multicolumn{2}{|c|}{ Wheat Varieties } \\
\hline $\mathrm{V}_{1}-$ Sujata & 51.84 \\
\hline $\mathrm{V}_{2}$-MP 3173 & 51.44 \\
\hline $\mathrm{V}_{3}$-MP 3288 & 50.60 \\
\hline
\end{tabular}

The data given in Table 1 clearly showed that various treatments viz pruning intensities in $D$. sissoo and wheat varieties did not showed any significant effect on germination percentage per meter row length.

Plant height: The height of plant is an index of growth. The observation on plant height was recorded at crown root initiation (CRI) Late tillers (LT), Late jointing (LJ), flowering (f), Milk (m), dough (D) and at harvest. The data were presented in Table 2 . 
Table 2: Effect of pruning intensities D. sissoo and wheat varieties on plant height (cm) at CRI, LT, LJ, F, M, D stage and at harvest in Agrisilviculture system.

\begin{tabular}{|c|c|c|c|c|c|c|c|}
\hline \multirow{2}{*}{ Treatment } & \multicolumn{6}{|c|}{ Plant height $(\mathrm{cm})$ at different stage of plant growth } & \multirow{2}{*}{ At harvest } \\
\hline & CRI & LT & LJ & $\mathbf{F}$ & M & D & \\
\hline \multicolumn{8}{|c|}{ Pruning treatment } \\
\hline P0 & 15.93 & 55 & 85.93 & 84.33 & 84.32 & 84.30 & 79.87 \\
\hline $\mathrm{P} 25$ & 15.00 & 56.2 & 87.93 & 87.07 & 86.2 & 85.27 & 85.13 \\
\hline P50 & 16.13 & 58.4 & 90.0 & 90.0 & 88.4 & 88.27 & 87.8 \\
\hline $\mathrm{P} 75$ & 17.00 & 61.0 & 90.07 & 90.07 & 89.47 & 88.4 & 88.27 \\
\hline Open- No tree & 17.93 & 64.4 & 95.53 & 94.53 & 94.47 & 94.07 & 93.00 \\
\hline $\mathrm{SEm} \pm$ & 0.24 & 0.69 & 0.83 & 0.81 & 0.85 & 0.96 & 1.1 \\
\hline $\mathrm{CD}$ at 0.05 & 0.72 & 20.06 & 2.48 & 2.43 & 2.54 & 2.87 & 3.2 \\
\hline \multicolumn{8}{|c|}{ Wheat varieties } \\
\hline V1-Sujata & 16.96 & 60.88 & 103.76 & 102.28 & 100.16 & 99.12 & 98.7 \\
\hline V2- MP 3173 & 16.08 & 58.6 & 82.40 & 85.40 & 82.40 & 82.16 & 82.2 \\
\hline V3 - MP 3288 & 15.84 & 57.52 & 80.52 & 80.53 & 80.52 & 80.16 & 79.6 \\
\hline SEm \pm & 0.79 & 2.81 & 3.98 & 4.00 & 4.06 & 4.1 & 2.4 \\
\hline CD at 0.05 & NS & NS & 11.34 & 11.4 & 11.41 & 11.42 & 6.8 \\
\hline
\end{tabular}

Data given in Table 2 showed that there was progressive increase in plant height in vegetative phase i.e. from CRI stage to late tillering stage after that growth of plant remain constant in reproductive phase and slight decrease towards maturity due to conversion of manufactured food material from vegetative phase to reproductive phase. Different pruning treatments showed significant effect on plant height in at different critical stages (i.e. CRI, LT, LJ; F,M \& dough) and at harvest. In all the stages of plant growth, plant height increased with increasing pruning intensity. Open condition recorded significantly higher plant height 17.93, 64.4, 95.53, $94.47,94.07 \mathrm{cms}$ whereas no pruning recorded significantly lowest plant height $(15.93,55,85.93,84.33,84.32$ and 84.3 $\mathrm{cm}$ ) in all the critical stage, of plant growth i.e. CRI, LT, LJ, $\mathrm{F}$, milk and dough stage, respectively. At harvest open condition recorded significantly taller plant $(93 \mathrm{~cm})$ and was significantly superior to different pruning treatment and no pruning. Among pruning treatments, $75 \%$ pruning recorded significantly higher plant height $(88.27 \mathrm{~cm})$ closely followed by $50 \%$ pruning $(87.8 \mathrm{~cm})$ and $25 \%$ pruning $(85.13 \mathrm{~cm})$ and was significantly superior to no pruning which recorded the lowest plant height $(79.87 \mathrm{~cm})$.

Variety Sujata recorded significantly taller plant height at late jointing stage $(103.76 \mathrm{~cm})$ flowering stage $(102.28 \mathrm{~cm})$, milk stage $(100.16 \mathrm{~cm})$ and dough stage $(99.12 \mathrm{~cm})$, whereas variety MP 3288 recorded significantly lowest plant height at all the stages (LT, LJ, F, M and dough stage) at par with MP 3173 .

At harvest, variety Sujata recorded significantly taller plant height $(98.68 \mathrm{~cm})$ as compared to MP $3173(82.16 \mathrm{~cm})$ and MP $3288(79.6 \mathrm{~cm})$ which were at par.

Table 3: Effect of different pruning intensities of D. sissoo and wheat varieties on number of tiller/meter row length at CRI, LT, LJ, F, M and dough stages of plant growth in Agri-silviculture system.

\begin{tabular}{|c|c|c|c|c|c|c|}
\hline \multirow{2}{*}{ Treatment } & \multicolumn{6}{|c|}{ Growth stage of plant } \\
\hline & CRI & Late tillering & Late jointing & Flowering & Milk stage & Dough stage \\
\hline \multicolumn{7}{|c|}{ Pruning treatment } \\
\hline $\mathrm{P} 0$ & 58.47 & 68.87 & 70.87 & 69.2 & 69.87 & 69.47 \\
\hline P25 & 61.47 & 71.33 & 76.73 & 76.2 & 76.0 & 75.93 \\
\hline P50 & 62.27 & 73.73 & 79.07 & 78.53 & 78.77 & 78.73 \\
\hline P75 & 62.60 & 75.07 & 82.00 & 81.07 & 80.8 & 80.07 \\
\hline Open-No tree & 66.07 & 80.13 & 86.13 & 85.80 & 85.63 & 85.60 \\
\hline $\mathrm{SEm} \pm$ & 1.03 & 1.30 & 0.86 & 0.92 & 0.78 & 0.81 \\
\hline $\mathrm{CD}$ at 0.05 & 30.07 & 3.88 & 2.57 & 2.75 & 2.33 & 2.42 \\
\hline \multicolumn{7}{|c|}{ Wheat varieties } \\
\hline V1-Sujata & 61.88 & 72.20 & 74.6 & 73.92 & 72.96 & 71.48 \\
\hline V2- MP 3173 & 62.60 & 76.68 & 83.72 & 83.64 & 83.12 & 82.44 \\
\hline V3-MP 3288 & 62.04 & 72.60 & 80.96 & 79.92 & 79.20 & 79.16 \\
\hline SEm \pm & 2.94 & 3.31 & 3.47 & 3.45 & 2.53 & 3.39 \\
\hline $\mathrm{CD}$ at 0.05 & NS & NS & NS & NS & NS & NS \\
\hline
\end{tabular}

\section{Number of tiller/meter row length-}

Number of tiller/meter row length increased from crown root initiation stage to late jointing stage and there after it decreased upto maturity (dough stage). Different pruning intensities showed significant effect on number of tillers/MRL in all the critical stages of plant growth i.e. CRI, LT, LJ, F, m and dough stages. Open condition recorded significantly higher number of tillers per meter row length at CRI (66.07), LT (80.13), LJ (86.13), F (85.8), M (85.63) and dough stage (85.6) and was significantly superior to other pruning treatments and no pruning. In the entire observations $75 \%$ pruning recorded significantly more number of tiller/m row length as compared to other pruning treatments. No pruning recorded significantly lowest number of tiller/meter row length at all the critical stages i.e. CRI (58.47), LT (68.87), LJ (70.87), F (69.2), M (69.87) and dough stages (69.47) of plant growth.

The effect of different wheat varieties on number of tiller/MRL was found not significant in all the critical stages of plant growth however variety MP 3173 recorded more number of tiller/MRL followed by MP 3288 whereas Sujata recorded the lowest number of tillers/MRL. 
AT And Post-Harvest Observations

Yield attributing characters

Effective tiller/MRL

Crop under open condition (no tree) recorded significantly higher number of effective tiller/MRL (84.0) at par with $75 \%$ pruning (77.4) and 50\% pruning (78) and was significantly superior to $25 \%$ pruning (75.1) and no pruning (60.3). As the pruning intensities increased, there was significant increase in number of tiller/MRL, hence, $75 \%$ pruning recorded significantly higher number of effective tiller/MRL (78.4) closely followed by $50 \%$ pruning (77) and $25 \%$ pruning (75.1) but significantly superior to no pruning (60.3) which recorded the lowest number of effective tiler/MRL (Table 4)

Different wheat varieties showed significant effect on number of effective tiller/MRL. Varieity MP 3173 recorded significantly higher number of effective tiller/MRL (81.9) than varieity MP 3288 (72.4) and Sujata (70.6) which were at par.

Table 4: Yield attributing character of wheat as influence of different pruning treatments and wheat varieties under agrihorticulture system of agroforestry.

\begin{tabular}{|c|c|c|c|c|}
\hline Treatment & No. of effective tiller/MRL & Length of ear head (cms) & Number of grians/ear head & 1000 grain weight (gms) \\
\hline \multicolumn{5}{|c|}{ Pruning treatment } \\
\hline P0 & 60.3 & 7.85 & 38.53 & 27.09 \\
\hline P25 & 75.1 & 8.5 & 40.8 & 32.37 \\
\hline P50 & 77.0 & 8.6 & 41.6 & 38.16 \\
\hline P75 & 78.4 & 8.63 & 42.8 & 35.51 \\
\hline Open- No tree & 84.0 & 8.85 & 45.39 & 39.55 \\
\hline SEM & 3.0 & 0.1 & 0.29 & 0.49 \\
\hline CD at 0.05 & 8.2 & 0.3 & 0.88 & 1.48 \\
\hline \multicolumn{5}{|c|}{ Wheat varieties } \\
\hline V1-Sujata & 70.6 & 8.4 & 42.0 & 37.6 \\
\hline V2-MP 3173 & 81.9 & 8.6 & 43.86 & 32.91 \\
\hline V3-MP 3288 & 72.4 & 8.5 & 39.8 & 35.49 \\
\hline SEM & 3.5 & 0.4 & 0.97 & 1.18 \\
\hline CD at 0.05 & 10.9 & NS & 2.78 & 3.35 \\
\hline
\end{tabular}

\section{Length of ear head}

Significantly maximum ear head length was recorded under open condition $(8.55 \mathrm{~cm})$ closely followed by $75 \%$ pruning $(8.63 \mathrm{~cm})$ and $50 \%$ pruning $(8.6 \mathrm{~cm})$ but significantly superior to $25 \%$ pruning $(8.5 \mathrm{~cm})$. Significantly minimum ear head length was recorded under no pruning (7.85).

Different wheat varieties showed no significant effect on length of earhead, however variety MP 3173 recorded longer earhead $(8.6 \mathrm{~cm})$ and Sujata which recorded the shorter ear head $(8.4 \mathrm{~cm})$.

\section{Number of grains/ ear head}

Open condition recorded significantly more number of grains/ earhead (45.30) and was significantly superior to different pruning treatments and no pruning. Among different pruning treatments, $75 \%$ pruning recorded significantly more number of grains/earhead (42.8) followed by $50 \%$ pruning (41.6) and $25 \%$ pruning (40.8). No pruning recorded significantly lowest number of grains/ earhead (38.53).
Variety MP 3173 recorded significantly more number of grains/ ear head at par with Sujata (42.8) but significantly superior to MP 3288 which recorded the lowest 1000 grain weight (39.8) at par with Sujata.

\section{0 grain weight (test weight)}

Pruning intensities showed significant effect on 100 grain weight significantly bolder seeds i.e. 1000 grain weight was recorded in open condition (39.55 gm) closely followed by $75 \%$ pruning $(39.51 \mathrm{gm})$ and was superior to other pruning treatments and no pruning. As the pruning intensity increased. 1000 grain weight increased hence $75 \%$ pruning recorded significantly higher test weight $(39.51 \mathrm{gm})$ closely followed $50 \%$ pruning $(38.16 \mathrm{gm})$ but significantly superior to $25 \%$ pruning (32.57 gm) and no pruning (27.09 gm) which recorded significantly lowest 1000 grain weight.

Variety Sujata gave significantly higher test weight $(37.6 \mathrm{gm})$ at par with MP 3288 (35.49 gm) but superior to MP 3173 which recorded the lowest test weight $(32.91 \mathrm{gm})$.

Table 5: Grain yield, straw yield and harvest index of wheat as influenced by different pruning intensities and different varieties in Agrisilviculture system.

\begin{tabular}{|c|c|c|c|}
\hline Treatment & Gran yield $\left(\mathbf{q} \mathbf{~ h a}^{-\mathbf{1}}\right)$ & Straw yield $\left(\mathbf{q} \mathbf{~ h a}^{-1}\right)$ & Harvest Index (\%) \\
\hline \multicolumn{4}{|c|}{ Pruning treatment } \\
\hline P0 & 17.74 & 34.53 & 33.92 \\
\hline P25 & 19.47 & 38.46 & 33.62 \\
\hline P50 & 21.27 & 41.54 & 33.83 \\
\hline P75 & 24.40 & 47.78 & 33.78 \\
\hline Open-No tree & 27.20 & 53.23 & 33.81 \\
\hline SEM & 0.66 & 4.21 & NS \\
\hline CD at 0.05 & 1.99 & 12.55 & 32.51 \\
\hline \multicolumn{5}{|c|}{ Wheat varieties } \\
\hline V1-Sujata & 20.86 & 43.27 & 34.96 \\
\hline V2- MP 3173 & 23.28 & 43.35 & 33.90 \\
\hline V3-MP 3288 & 21.91 & 42.71 & 0.25 \\
\hline SEM \pm & 0.73 & 4.42 & 0.72 \\
\hline CD at 0.05 & 2.09 & NS & \\
\hline
\end{tabular}




\section{Grain yield (q ha' $\mathbf{~ h a ~}^{-1}$}

Maximum grain yield of wheat was recorded when grown under open condition (27.20 q ha-1). Among different pruning intensities, significantly maximum grain yield was recorded under $75 \%$ pruning $\left(24.4 \mathrm{q} \mathrm{ha}^{-1}\right)$ which inturn was significantly superior to $50 \%$ pruning $\left(21.27 \mathrm{q} \mathrm{ha}^{-1}\right)$ and $25 \%$ pruning (19.47 $\left.\mathrm{q} \mathrm{ha}^{-1}\right)$. No pruning recorded significantly lowest grain yield $\left(17.74 \mathrm{q} \mathrm{ha}^{-1}\right)$. The percent reduction in grain yield under no pruning $25 \%, 50 \%$ and $75 \%$. Pruning as compared to open condition was $34.75 \%, 28.41 \%, 21.80 \%$ and $10.29 \%$ respectively. Similar result was also incurred by Newaj et al., (2007) ${ }^{[4]}$.

Variety MP-3173 recorded significantly higher grain yield (23.28 $\left.\mathrm{q} \mathrm{ha}^{-1}\right)$ at par with MP 3288 (21.91 q ha-1) but significantly, superior to variety Sujata which recorded significantly lowest grain yield $\left(20.86 \mathrm{q} \mathrm{ha}^{-1}\right)$. The percent reduction in grain yield under Sujata, MP 3288 as compared to MP 3173 was $10.3 \%$ and $7.6 \%$ respectively.

\section{Straw yield (q ha $\left.{ }^{-1}\right)$}

Open condition recorded significantly higher straw yield (53.23 q ha-1) and was significantly superior to different pruning treatments and no pruning. Among different pruning treatment, $75 \%$ pruning recorded maximum straw yield (47.78 $\left.\mathrm{q} \mathrm{ha}^{-1}\right)$ which inturned was superior to $50 \%$ pruning (41.54 $\left.\mathrm{q} \mathrm{ha}^{-1}\right)$ and $25 \%$ pruning (38.46 q ha-1) which were at par. No pruning recorded significantly lowest straw yield of $34.53 \mathrm{q} \mathrm{ha}^{-1}$. The percent reduction in straw yield under no pruning, $25 \%$ pruning, $50 \%$ pruning, $75 \%$ pruning over open condition (no tree) was $35.13 \%, 27.74 \%, 21.96 \%$ and $10.23 \%$ respectively.

Wheat varieties showed no significant effect on straw yield, however variety Sujata recorded higher straw yield as compared to variety MP 3173 and MP 3288.Interaction between pruning treatments and varieties was found not significant.

\section{Harvest Index}

Different pruning intensities showed no significant effect on harvest index. Different wheat varieties showed significant effect on harvest index. Variety MP 3288 recorded significantly higher harvest index (34.96) followed by MP 3288 (33.90). Variety Sujata recorded lowest harvest index (32.51). A similar result was also given by Couto and Gomes (1995) ${ }^{[1]}$ and Newaj et al., (2007) ${ }^{[4]}$.

\section{Reference}

1. Couto L, Gomes JM. Intercropping Eucalyptus with beans in Minas Gerais, Brazil. International Tree Crop Journal. 1995; 8(213):83-93.

2. Dhyani SK, Narain P, Singh P. Studies on root distribution of five multipurpose tree species in Doon Valley, India. Agroforestry Systems. 1990; 12:149-161.

3. Hagger JP, Tanner EVJ, Beer JW, Kass DCL. Nitrogen dynamics of tropical agroforestry and annual cropping systems. Soil Biology and Biochemistry. 1993; 25:13631378.

4. Ram Newaj Dar SA, Bhargava MK, Yadav RS, Ajit. Effect of management practices on growth of white siris (Albizia procera), grain yield of intercrops, weed population and soil fertility changes in Agri-silviculture system in semi-arid India. Indian Journal of Agricultural Sciences. 2007; 77(7).

5. Singh A, Dhanda RS, Ralhan PK. Performance of wheat varieties under popular (Populus deltoides Bartr.) plantations in Punjab (India). Agroforestry Systems. 1993; 22:83-86. 